\title{
Quantifying and Predicting Reactive Transport of Uranium in Waste Plumes (EMSP Project 73775)
}

Lead-Investigator: Jiamin Wan" (jmwan@lbl.gov)

Co-investigators: $\quad$ Tetsu Tokunaga ${ }^{\#}$, Carl Steefel ${ }^{\#}$, and Peter Burns ${ }^{*}$

${ }^{\#}$ Lawrence Berkeley National Laboratory ${ }^{*}$ University of Notre Dame

\section{Research Objectives}

The Hanford Site is the DOE's largest legacy waste site, with uranium (U) from plutonium processing being a major contaminant in its subsurface. Accident release of highly concentrated high level wastes (e.g. $0.5 \mathrm{lb} \mathrm{U}(\mathrm{VI}) / \mathrm{gal}$ ) left large quantities of $\mathrm{U}$ in the vadose zone under tank farms (e.g. 7-8 tons U(VI) under tank BX-102 (Jones et al., 2001)). The U contaminantion has been found in groundwater in both 300 and 200 Areas of Hanford, indicating $\mathrm{U}(\mathrm{VI})$ was/is mobile. Because excavation costs are enormous, this $\mathrm{U}$ will likely be left inground for the foreseeable future. Therefore, understanding the contamination processes and the resulting $U$ spatial and temporary distributions and mobility in the heavily contaminated Hanford site is needed in order to forecast its future transport. The overall objective of this research is to develop an experimentally supported conceptual model of $U$ reactive transport, during and after the tank leakage, at heavily U-contaminated areas of the Hanford vadose zone. The conceptual model will incorporate key geochemical and physical controls on the contamination process, explain the current distribution of $U$ in the vadose zone, and guide predictions of its future mobility under the influence of natural recharge. We do not seek to predict the complex flow geometry of any specific waste plume. Instead, our work is trying to identify the hierarchy of processes relevant along $U$ waste plume paths.

\section{Research Progress and Implications}

This report summarizes progress during the first two years (2004-2005) of our project. In pursuit of our research objective, we chose to simulate the tank BX-102 leakage/over-fill event (the largest single event of $U$ release in the country, left 7-8 tons of $U$ in the vadose zone). We synthesized the Metal Waste solution based on the historical recipe. The Metal Waste solution contained $110 \mathrm{mM} \mathrm{U}(\mathrm{VI})$, 3.6 M sodium, $0.6 \mathrm{M}$ carbonate, and had a $\mathrm{pH}$ of 10.4. The waste solution was injected into a Hanford sand column ( 0.5 meter long) at $70^{\circ} \mathrm{C}$. Flow was stopped prior to emergence of the waste solution in order to collect samples of pore solutions (suspensions) and sediments along the plume length. The profile of extracted pore solutions from a laboratory U plume immediately following sampling (without aging) is shown in Figure 1. Large quantities of $U$ colloids formed at the plume front. The SEM photograph (Figure 2) shows two types of morphologies; sphere-like particles of about $200 \mathrm{~nm}$ in diameter, and plate-like particles up to a few $\mu \mathrm{m}$. The EDS analyses found that $U$ is a major component in both phases. Using synchrotron micro-XRD, the plate-like phase was identified as sodium uranyl carbonate. Shown in Figure 3 are several of the measured properties along plume profiles; normalized electrical conductivity (EC, normalized to that of the influent waste solution), $\mathrm{pH}$, and turbidity. The normalized EC values are close to zero for the displaced soil water, and approach 1 for the plume body pore solution. The inflection point of the EC profile is used to identify the plume front, where the high ionic strength waste solution mixes with the low salinity soil water. The 
plume $\mathrm{pH}$ decreases to 7 at the plume front, 3 units lower than the $\mathrm{pH}$ of initial waste solution $(\mathrm{pH} 10.4)$ and one unit lower than the $\mathrm{pH}$ of the displaced native sediment water $(\mathrm{pH}$ 8.4). Turbidity, a qualitative measure of particle concentration, reaches a peak value as high as 10,000 NTU (independently measured suspended mass content $=5 \%$ ). The massive $U$ precipitation at the plume front is caused by lower $\mathrm{pH}$ in the plume (as $\mathrm{pH}$ is lowered from 10 to 7 , the solubility of a common U(VI)-oxides decrease by 3 orders of magnitude). Our aged (3 and 12 months) $\mathrm{U}$ column samples have recently been analyzed, and show a slightly decreased $\mathrm{pH}$ in the body of the plume, no changes at the $\mathrm{pH}$-neutral front and absence of the mobile colloidal fraction (deposition onto sediment grains). More sample analyses are in progress.

Reactive transport modeling of the columns experiments was carried out by first matching the time-dependent liquid saturation and non-reactive tracer fronts in the column. The initially partially saturated column becomes fully saturated with water up to about 0.3 meters as the simulated tank solution is injected from below. Matching of the solution $\mathrm{pH}$ was carried out by including various mineral precipitation and dissolution reactions, the most important of which is calcite. Calcite precipitates because of the high bicarbonate in the injection solution and because of the desorption of $\mathrm{Ca}^{+2}$ from cation exchange sites on the clays as a result of the elution of the high $\mathrm{Na}^{+}$, which competes for exchange sites with the $\mathrm{Ca}^{+2}$. The precipitation of calcite releases hydrogen ion, thus lowering the $\mathrm{pH}$ (Figure 4). The simulations also predict the precipitation of brucite as a result of the high $\mathrm{pH}$ of the injection solution and the desorption of $\mathrm{Mg}^{+2}$ from exchange sites in the sediment. Other reactions, while less important for modeling of the $\mathrm{pH}$, include the precipitation of various uranium phases, including uranium phosphate and schoepite (Figure 4). The simulations predict the precipitation of minor amounts of sodium uranium carbonate, a phase identified by XRD in the columns, but only upstream of the calcite desorption front, since the precipitation of calcite reduces bicarbonate in solution and de-stabilizes the sodium uranium carbonate.

Although $\mathrm{U}(\mathrm{VI})$ geochemistry has been extensively studied in equilibrium and nearequilibrium systems, our new results showing flow and transport induced heterogeneity of $U$ distribution and speciation along the plume path have not been previously recognized. Through this project we expect to develop the experimental, conceptual, and numerical tools to predict field scale U spatial distribution, speciation, mineralogy, and future mobility.

\section{Acknowledgments}

We thank Jeffrey Serne (PNNL) for providing the U Metal Waste solution recipe and helpful discussion on its synthesis, Tony Lanzirotti (University of Chicago) for conduction the synchrotron micro-XRD analyses of U-containing colloid phase (beamline X26A, NSLS), and Joern Larsen, Yongman Kim, and Tom He (LBNL) for column experiment operation and analyses. 


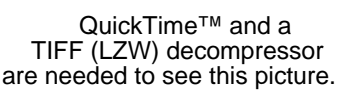

Figure 1. A photograph of a profile of extracted pore solutions from a simulated $U$ plume at the time of initial plume formation (without aging). The flow direction is towards the right. Note the large quantity of $U$ colloids formed at the plume front (unpublished).

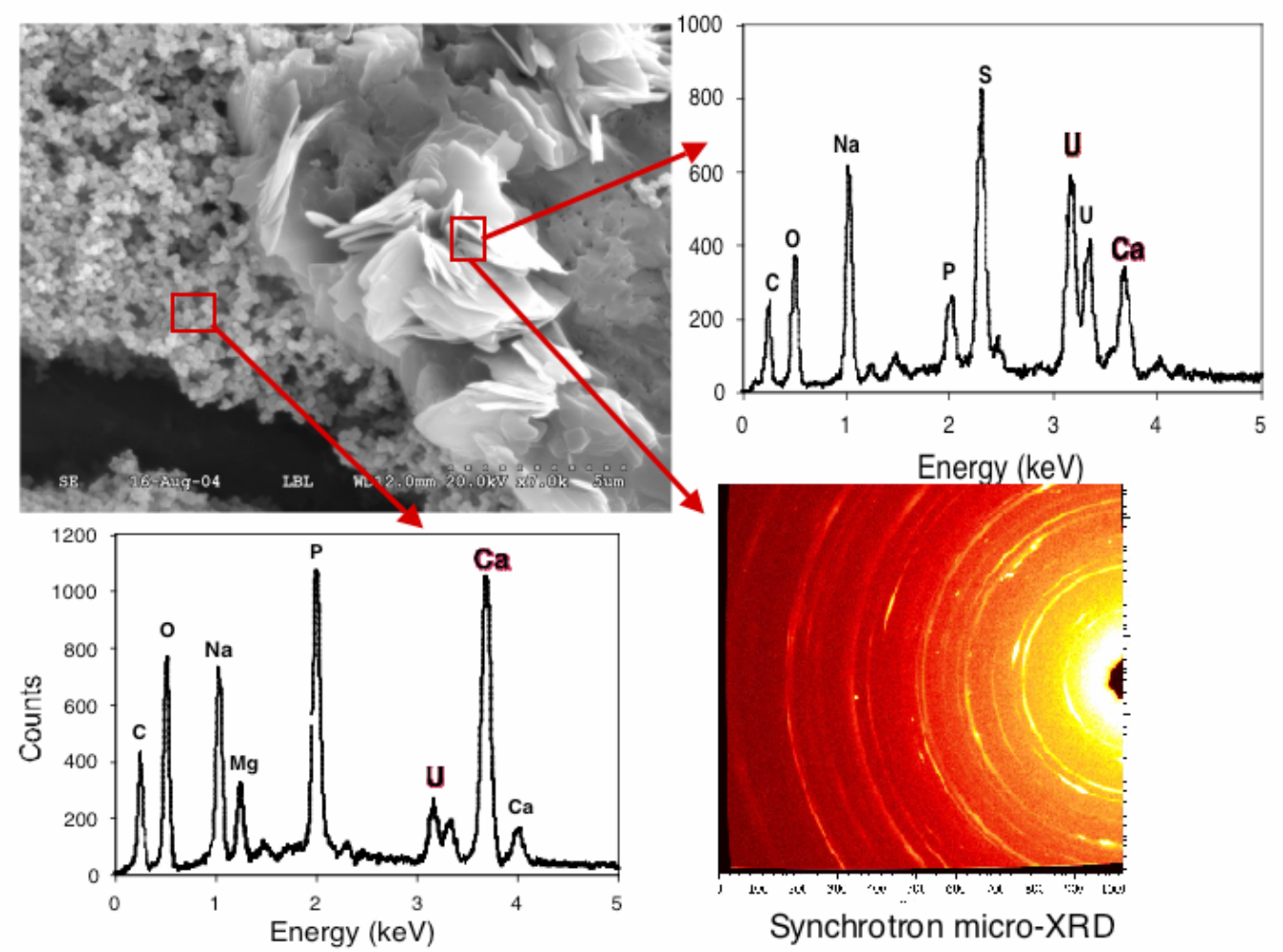

Figure 2. Characterization of the plume front colloids: morphology, chemical composition, and structure (unpublished). 
Figure 3. Measured profiles of normalized EC, $\mathrm{pH}$ and turbidity, along the plume length (unpublished).
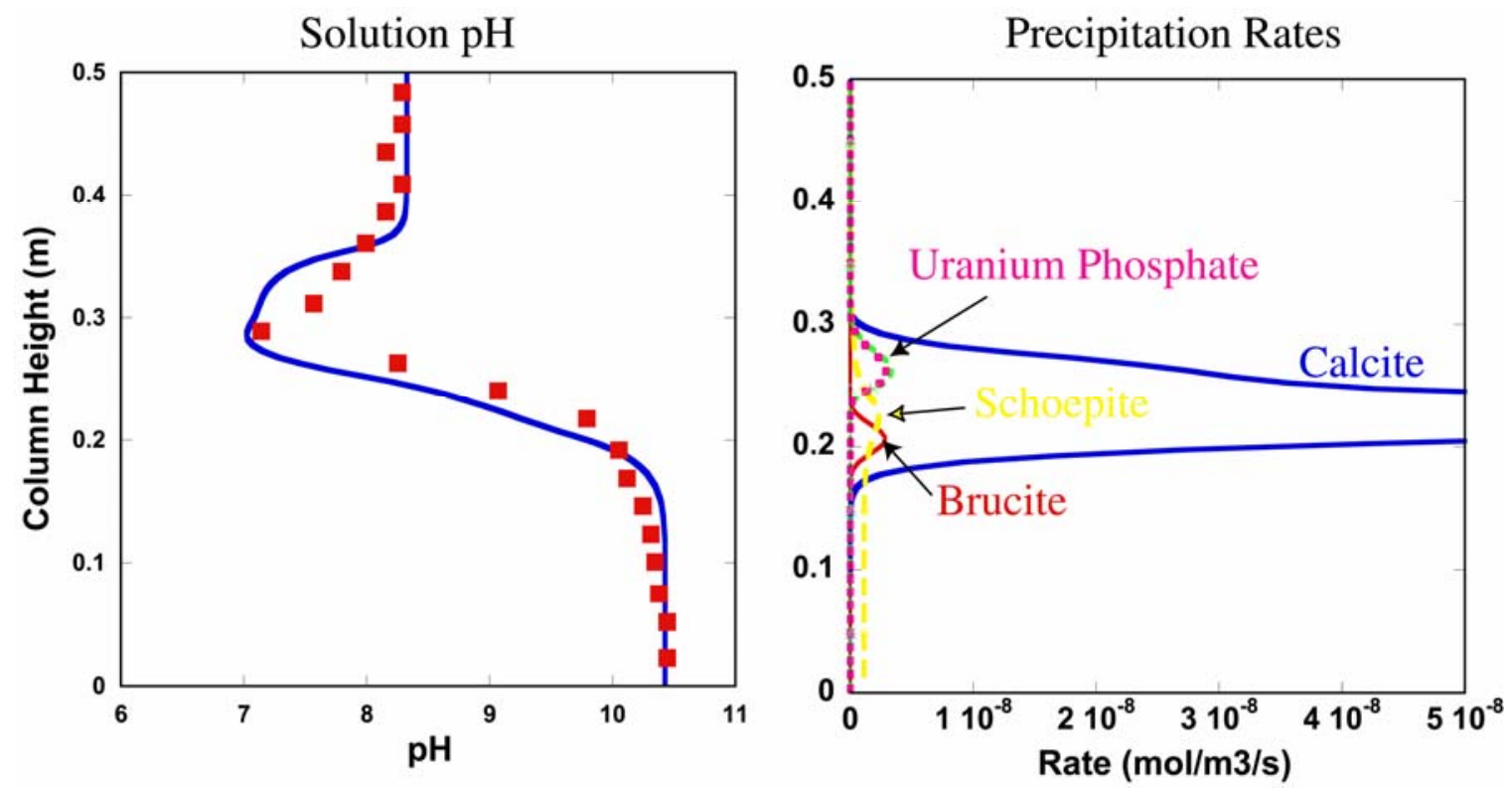

Figure 4. Example of reactive transport modeling of the columns experiments (unpublished). 